\title{
Reino y reinado de Dios en el mensaje de Jesús
}

Ningún tema neotestamentario ha sido y es objeto de tan reiterado y apasionado estudio como el del «Reino» y «Reinado de Dios»-(=Basileia tô Theoû) en el mensaje de Jesús: Además de los comentarios a la segunda súplica del Padrenuestro ${ }^{1}$, su análisis ha sido abordado por artículos generales ${ }^{2}$ así como por específicos estudios articulísticos y monográficos ${ }^{3}$ sobre dicha

1. Además de los comentarios a Mt 6,10a y a Lc 11,2c, citamos solamente: STr.-BiLl., I 418s; P. FIEBIG, Das Vaterunser, Gütersloh 1927,73-76; E. LOHMEYER, Das Vater-Unser, Zürich ${ }^{3}$ 1952,59-75; H. van den BussCHE, El Padrenuestro, Bilbao 1964, 81-87; H. SCHURMANN, La Prière du Seigneur, Paris 1967, 41-45; J. JeREMIAS, Das Vater-Unser, Stuttgart ${ }^{2} 1967,20$ s; Id., Neutestamentliche Theologie, Gütersloh 1971, 192s (trad. españ., 232-34) J. CARMIGNAC, Recherches sur le «Notre Père», Paris 1968, 89-102; S. SABUGaL, El Padrenuestro, Salamanca 1982, 204215; Id., La oración del Señor. Historia y Exégesis, Madrid 1974, 000-00.

2. Cf. W. SANDAY, art. Jesus-Christ, en: «Hasting's DB», II 603-53; 619-22; J. ORR, art., Kingdom of God, en Ib., 844-56: 849-55; J.-B. FREY, art. cit., (DB, V), 1243-53; K.L. SCHMIDT, art. Basileia, en: ThWNT, I 579-92: 582ss; H. ConZELMANN, art. Jesus Christus, en RGG, III ${ }^{3}$ 619-53: 641-44; Id., art. Reich Gottes, en: ib., V ${ }^{3}$ 914-18: 914-16; R. SCHNACKENBURG, art. Basileia, III. Jesuverkündigung, en: LThK, II ${ }^{2}$ 26-29; Id., art. Jesus Christus, en: ib., $\mathrm{V}^{2}$ 922-40: 925s; Id., art. Reino de Dios, en: DTB 894-901; J. PRADO, Dominio terreno universal de Dios según el NT, en: EB II 994-98: 94-96; Id., art. Reino de Dios, en: ib., VI 150-54: 152ss; P. HưNNERMANN, art. Reino de Dios, en: SM, V 880-97: 885-87 (bibliogr.); U. Luz, art. Basileia, en: EWNT, I 481-91: 483-87 (bibliogr.); A. FeullLET, art. Régne de Dieu. III: Evangiles Synoptiques, en: DBS, X 61-165.

3. Cf. H. WINDISCH, Die Sprüche von Eingehen in das Reich Gottes, en: ZNW 27 (1928) 163-92; J.Y. CAMPBELL, The Kingdom of God has come, en: ExpT 48 (1936-37) 91-94; Ch. H. DodD, The Kingdom of God has come, en: ib., 138-41; J.A. ONATE, art. cit., (supra, n. 8), 35868; M. Burrows, Thy Kingdom come, en: JBL 74 (1955) 1-8; F. Mussner, Gottesherrschaft und Sendung Jesu nach Mk 1,14f., en: «Praesentia salutis», Düsseldorf 1967, 81-93; A. FEulLLET, El Reinado de Dios y la persona de Jesús según los Evangelios Sinópticos, en: «Introducción a la Biblia», II, Barcelona 1970, 689-727: 691-99; Id., Le Régne de Dieu et les miracles de Jésus d'après les évangiles synoptiques, en: EspritVie 87 (1977) 655-69; Id., Le caractèr purement réligieux et universel du règne de Dieu d'après les évangiles synoptiques, en: Divinitas 22 (1978) 153-75; G. KLEIN, «Reich Gottes» als biblischer Zentralbegriff, en: EvTh 30 (1970) 642-70: 654-59; E. GRÄSSER, Zum Verständnis der Königsherrschaft, en: ZNW 65 (1974) 3-26; I. MAISCH, Die Botschaft 
temática, estudiada asimismo al nivel redaccional de los tres primeros evangelistas ${ }^{4}$, a cuyos análisis se suman los realizados en el contexto de las teologías neotestamentarias ${ }^{5}$, de las monografías sobre el Jesús histórico ${ }^{6} \mathrm{y}$ su mensaje prístino ${ }^{7}$, sus parábolas ${ }^{8}$, su autoconciencia mesiánica y esperan-

Jesu von der Gottesherrschaft, en: "Gottesherrschaft und kommendes Reich» (Fs. A. Vögtle), Stuttgart 1975, 27-48. A estos estudios se suman las monografías de: J. WEISs, o.c., 36-210: B. Bartmann, Das Himmelreich und sein König nach den Synoptikern, Paderborn 1904; R. OTto, The Kingdom of God and the Son of Man (trad. ingl.), London 1938, espec., 45-155; H. WENDLAND, The Kingdom of God in history, London 1938, 145-94; J. BonsirvEN, Règne de Dieu, Paris 1957, 43-60; G. LUNDSTROM, The Kingdom of God in the Teaching of Jesus. A history of interpretarion, Edimburgh-London 1963; N. PERRIN, The Kingdom of God in the teaching of Jesus, London 1963, espec., 157-203; Id., Rediscovering the teaching of Jesus, London 1967, 55-108; F.W. MAIER, Jesus-Lehrer der Gottestherrschaft, Würzburg 1965, 43-98: R. SCHNACKENBURG, Gottesherrschaft und Reich, Freiburg ${ }^{4} 1965,49-180$ (trad. españ., 65-236); G.E. LADD, Jesus and the Kingdom, London 1966, 99-335; A. SCHWEITZER, Reich Gottes und Christentum, Tübingen 1967, 98-145; H. FLENDER, Die Botschaft Jesu von der Herrschaft Gottes, München 1968, 30 65; R.H. Hiers, The Kingdom of God in the synoptic Tradition, Gainesville 1970, espec., 22-97; Id., The historical Jesus and the Kingdom of God, Gainesville 1973, 11-46.59-64; B.D. CHILTON, God in Streng. Jesus'anouncement of the Kingdom (StNTU, 1) Freistadt 1979; J. SCHLOSSER, Le Règne de Dieu dans les dites de Jésus, Paris 1980.

4. Mateo (Cf. S. Sabugal, La Oración del Señor, 000-00: bibliogr., 000, n. 39), Lucas (Cf. S. SABugal, La Oración del Señor, 000-00: bibliografía 000, n. 43), Marcos: A.M. AMBro$\mathrm{ZIC}$, The hidden Kingdom. A redactional critical study of the references to the Kingdom of God in Mark'Gospel, Washington 1972; W. KeLBER, The Kingdom in Mark, Philadelphia 1976; J. CARMIGNAC, Mirage... (infra, n. 9), 23-34.

5. Cf. M. Meinertz, Teología del NT, Madrid 1963, 25-66; R. BultmanN, Theologie des $N T$, Tübingen ${ }^{5} 1965,2-21$ (trad. españ., Salamanca 1981, 41-59); H. CoNZELMANN, Grundriss der Theologie des NT, München 1968, 125-34; W.G. KUMMEL, Die Theologie des NT nach seinen Hauptzeugen (NTD Ergänzungsreihe, 3), Göttingen 1969, 29-35.43-52; J. JEREMIAs, Neutestamentliche Theologie, Gütersloh 1971, 40-43.99.110 (trad. españ., 46-50.119-32); M. GARCíA CoRDERO, Teología de la Biblia, II 1972, 168-97; K.H. SCHELKLE, Teología del NT (trad. españ.), Barcelona 1975, III 59s; IV 40-48; L. GoppeLT, Theologie des NT, I, Göttingen 1975, 94-127; E. LoHSE, Teología del NT (trad. españ.), Madrid 1978, 41-48.

6. Cf. A. Schweitzer, Geschichte der Leben-Jesu-Forschung, Tübingen ${ }^{2} 1913$, 233-35.390-443; R. BultmanN, Jesus, Tübingen 1926 (repr. 1964), 27-51; M. Dibelius, Jesus, (1939) Berlin 41966, 52-73; V. TAYLOR, The life and ministry of Jesus, London 1961, 66-70; G. BoRNKAMM, Jesus von nazareth, Stuttgart ${ }^{7} 1965,58-87$ (trad. españ., Salamanca 1975, 67-100); J. BLANK, Jesus von Nazareth, Freiburg 1972, $42-50$ (trad. españ., Madrid 1973, 50-58); W. KASPER, Jesus der Christus, Mainz 1974, 83-103 (trad. españ., Salamanca 21978, 86-107).

7. Cf. G. Dalman, Die Worte Jesu, Leipzig 1930, 83-119; C.J. Cadoux, The historic mission of Jesus, London 1941, 107-109; T.W. MANSON, The sayings of Jesus, London 1949, 169.303-5; E. Percy, Die Botschaft Jesu, Lund 1953, 19-28; R.H. Fuller, The mission and achievement of Jesus (StBTh, 12) London 1954, 20-78; X. LEON-Doufour, Les Evangiles et l'histoire de Jésus, Paris 1963, 378-96 (trad. españ., 334-49); E. JÚNGEL, Paulus und Jesus, Tübingen ${ }^{3}$ 1967, 87-215: 139ss; A.M. HunTER, The Work and Words of Jesus, London 21973, 90-100.

8. Cf. Ch. H. DoDD, The Parables of the Kingdom, London ${ }^{2} 1961,21-59.140-56$ (trad. españ., Madrid 1974, 42-82.177-83; J. JEREMIAS, Die Gleichnisse Jesu, Göttingen ${ }^{7} 1965,115-217$ (trad. españ., Estella 1970, 143-265); A.M. HUNTER, Interpreting the parables, London ${ }^{2} 1969$, 42-91. Un comentarista católico clasifica todas las parábolas de Jesús bajo los temas 1) «El Reina- 
za escatológica ${ }^{9}$ así como su enseñanza ética ${ }^{10} \ldots$ ¡ Una muy nutrida y no menos densa bibliografía! ${ }^{11}$. Merecidamente dedicada, por otra parte, al estudio de lo que, en concorde opinión de los autores, constituye «el tema central de la predicación de Jesús» ${ }^{12}$. Nada de extraño, pues, su presencia en la segunda súplica del Padrenuestro, cuya rítmica composición binaria muestra ya, que en ella formuló efectivamente Jesús una de las ideas centrales de su mensaje. Es lo que refleja, por lo demás, la estadística del uso, que de aquella expresión hace la literatura neotestamentaria y, en particular, evangélica ${ }^{13}:$ Los Evangelios 65 veces - siempre en labios de Jesús con pocas excepciones (Mc 15,43; Lc $17,20 \mathrm{a} ; 19,11)$ - , de las cuales 9 veces en la fuente $Q^{14}, 14$ veces en $\mathrm{Mc}^{15}, 27$ veces en la redacción de $\mathrm{Mt}{ }^{16}$, 15 veces en la redacción de Lc ${ }^{17}$ y 2 veces en Jn $(3,3.5)$; el resto del NT usa esa expresión 19 veces, de las cuales 7 veces en Act ${ }^{18}, 9$ veces en las Ep. paulinas ${ }^{19}, 1$ vez en las Ep. católicas (Sant 2,5) y 2

do de Dios» y 2) «Los deberes de los sujetos del Reinado de Dios»: D. BuzY, Les paraboles (Verbum salutis, 6), Paris ${ }^{16} 1948$, p. XVIIs.

9. Cf. A. Schweitzer, Die Messianitäts- und Leidensgeheimnis. Eine Skizze des Lebens Jesu, Tübingen-Leipzig 1901, 13-34; H.D., WENDLAND, Die Eschatologie des Reiches Gottes bei Jesus, Gütersloh 1931, 10ss; H.A. GuY, They New Testament doctrine of the last things, Oxford 1948, 43-50.66-76; W.G. KUMMEL, Verheissung und Erfullung. Untersuchungen zur eschatologischen Verkündigung Jesu (AbhThANT, 6), Zürich ${ }^{3} 1956,13-80.98-147$; J. BECKER, Das Heil Gottes (StUNT, 3), Göttingen 1964, 197-217; E. BAMMEL, Erwägungen zur Eschatologie Jesu, en: StEv 3 (1964) 3-32: 6-19; O. CullmanN, Le salut dans l'histoire, Neichâtel 1966, 190-236; E. GRÄSSER, Die Naherwartung Jesu (SBS, 61), Stuttgart 1973, 37-141; J. CARMIGNAC, Le Mirage de l'Eschatologie. Royauté. Règne et Royaume de Dieu... sans Eschatologie, Paris 1979, 23-63.8391.

10. Cf. R. Schnackenburg, El testimonio moral del Nuevo Testamento (trad. españ.), Madrid 1965, 9-138, espec., 9-42; H.D. WENDland, Ethik des Neuen Testaments (NTD Ergänzungsreihe, 4), Göttingen 1970, 4-33; H. MERKLEIN, Die Gottesherrschaft als Handlungsprinzip. Untersuchungen zur Ethik Jesu, Würzburg 21981, 47-107.166-72.

11. Para la historia de su interpretación, además de la monografía de G. LundSTROM, o.c. (supra, n. 3), Cf. N. Perrin, Kingdom, 13-157; R. SCHNACKenBURG, art. cit. (DTB), 895s; G.E. LADD, o.c., 3-38; J. SCHLOSSER, o.c., 47-64.

12. J. JEREMIAS, Theologie NT, 43.99 .106 (trad. españ., 50.119.127).

13. Cf. M. PERrin, Rediscovering, 60-62; J. JeremIAs, Theologie NT, 40 (trad. españ., 46); H. MERKLEIN, o.c., 21-25; J. SchlOSSER, o.c., 42-47. Un rápido análisis de todos esos textos ofrece J. CARMignac, Mirage, 23-82.

14. Lc 6,20 (=Mt 5,3); Lc 11,2 (= Mt 6,10); Lc 12,31 (=Mt 6,33); Lc 13,29 (Mt 8,11); Lc 9,2 (=Mt 10,7); Mt 11,11 (=Lc 7,28). 12 (=Lc 16,16); Lc 11,20 (=Mt 12,28); Lc 13,20 (= Mt 13,33). 15,43 .

15. Mc 1,15par.; 4,11par. 26.30par.; 9,1par. 47; 10,14.15.23.24.25; 12,34: 14,25par.;

16. Mt $5,10.19$ a.b.20; 7,21; 8,12; 13,19.24.38.43.44.45.47.52;16,19;18,1.3.4.23;19,12; 20,$1 ; 21,31.43 ; 22,2 ; 23,13 ; 24,14 ; 25,1$.

17. Lc 4,$43 ; 9,60.62 ; 10,7.11 ; 12,32 ; 13,28 ; 17,20$ a.b.21; 18,$29 ; 19,11 ; 21,31 ; 22,16.18$.

18. Act 1,$3 ; 8,12 ; 14,22 ; 19,8 ; 20,25 ; 28,23.31$.

19. 1Tes 2,$12 ; 2$ Tes, $5 ; 1$ Cor 4,$20 ; 6,9.10 ; 15,50 ;$ Gál 5,21 ; Rm 14,17; Col 4,11; Ef 5,5 (en $2 \operatorname{Tim} 4,18$ se trata del «Reino» del «Señor» Jesús: Cf. 4,8 ). 
veces en el Apocalipsis $(11,15 ; 12,10)$. Esta estadística muestra que el empleo de «Basileia toû Theoû» es del todo parco en Jn así como en la literatura extra-evangélica: No es, pues, mera herencia judaica ni producto de la fe cristiana. Su frecuencia en las cuatro fuentes de la tradición sinóptica, unánimes en usarla casi siempre en labios de Jesús así como en giros o locuciones literarias ignoradas por la literatura judaica y específicamente cristiana ${ }^{20}$, es por el contrario indicio seguro de que «Basileia toû», en su doble significado de «Reino» ${ }^{21} \mathrm{y}$ «Reinado ${ }^{22}$ de Dios», es una de las «características de la mismísima voz» así como «de la enseñanza de Jesús» ${ }^{23}$. ¿En qué sentido?

\section{1. «El Reino de Dios»}

Si en la literatura veterotestamentaria (con la excepción de Sab 10,10) y judaica «malkut» $\mathrm{y}$ «basileia» nunca designan «el Reino de Dios», esta designación envuelve «basileia» en el contexto de la instrucción de Jesús a sus discípulos sobre las bienaventuranzas (Lc 6,20=Mt 5,3) y la edificación de su «Iglesia» (Mt 16,19), sobre el divino don del Reino (Lc 12,32), las condiciones para entrar en él ${ }^{24}$ y ocupar un puesto mayor o menor ${ }^{25}$ en su futuro banquete ${ }^{26}$; idéntica designación arropa «basileia» también en el contexto del diálogo de Jesús con la gente (Mt 11,12=Lc 16,16; Mc 12,34) y de su polémica con los adversarios (Mt 21,31; 23,12), así como de las parábolas sobre el labrador paciente (Mc 4,26-29), el grano de mostaza (Mc 4,30-32par) y la levadura (Mt 13,33 = Lc 13,20s), el tesoro escondido (Mt 13,44) y la perla preciosa (Mt 13,45s), la zizaña (Mt 13,24-30.36-43) y la red (Mt 13,47-50), los dos hijos (Mt 21,28-32), los talentos (Mt 25,14-30; Cf. Lc 19,11-27) y el nupcial banquete mesiánico (Lc 14,15-24par; Mt 25,1-13). ¿Qué significado concreto traduce

20. Cf. J. JeRemias, o.c., 41 s. 100 (trad. españ., 48s. 120). Por otra parte las cuatro fuentes de la tradición sinóptica emplean «Basileia» en labios de Jesús, para designar «Reino de Dios» (Cf. infra, n. 21) y -menos frecuentemente - su «Reinado» (Cf. infra, n. 22). La distinción de este doble significado de «Basileia toû Theou» en la tradición evangélica. - generalmente no tenido en cuenta por los autores-, es de trascendental importancia, para detectar con objetividad su diverso contenido teológico: $\mathrm{Cf}$. a este respecto J. CARMIGNAC, Mirage..., 23-65.

21. Mc 4,26.30par; 9,47; 10,14-15par.23-25par.; 12,34; 14,25 (=Mt 26,29); 15,43 (= Lc 23,51); Lc 6,20 (=Mt 5,3); Mt 11,11 (=Lc 7,28); Lc 13,20-21 (=Mt 13,33). 28-29 (=Mt 8,11); Mt 8,12-13 (=Lc 16,16); Mt 5,19-20; 7,21; 13,24.38.43.44.45.47.52 (Cf. Mc 12,34); 16,19; 18,3-4; 21,$31 ; 22,2 ; 23,13 ; 25,1.34$; Lc 12,$32 ; 14,15 ; 22,16.29$.

22. Mc 1,15 (= Mt 4,17); 4,11par.; 9,1 par.; Lc 9,2 (= Mt 10,7); 10,9.11; 11,2 (=Mt 6,10); 11,20 (=Mt 12,28); Mt 18,23; 19,12; 20,1;24,14; Lc 4,43; 8,1; 9,60.62; 17,20a.b.21; 18,29; 22,18.

23. J. Jeremias, Theologie NT, 40-43 (trad. españ., 46-50); N. Perrin, Rediscovering, 62.

24. Cf. Mc 9,47; 10,14-15par.; Mt 5,20; 7,21; 25.31-46.

25. Cf. Mt 5,19; 11,11 par.; 18,1-5par.

26. Cf. Mt 8,11-12par.; Mc 14,25par.; Lc 22,29. 
en estos textos aquella designación? Digamos de inmediato que, en la concepción de Jesús, «el Reino de Dios» se identifica esencialmente con

\section{1) El Reino del Padre}

Es lo que afirma explícitamente el Maestro, cuando asegura a sus discípulos que «al Padre le ha parecido bien darles el Reino» (Lc 12,32) escatológico, que preparó a su Hijo (Cf. Lc 22,29) y, «desde la creación del mundo», a los justos (Cf. Mt 25,34), donde - «en el Reino de su Padre»- éstos «brillarán como el sol» (Mt 13,43) y donde — «en el Reino de su Padre»-Él mismo beberá con sus discípulos el «nuevo» vino de la salvación mesiánica (Mt 26,29). Nada de extraño, pues, si «el Reino» de Dios «se asemeja a un rey, que celebró las bodas de su hijo» (Mt 22,2), siendo la conducta del Padre celeste para con sus hijos del todo análoga al comportamiento de un rey o señor para con sus siervos (Mt 18,23-34). Porque esto es exactamente «el Padre» de Jesús: $E l$ «Señor del cielo y de la tierra» (Mt 11,25b=Lc 10,21b), es decir, «el gran Rey», quien, desde "su ciudad» (= Jerusalén) o capital regia, reina con paternal providencia sobre todas las creaturas (Cf. Mt 6,25-33par; 10,28-31), pues tiene al «cielo por su trono» y a «la tierra por escabel de sus pies» (Mt 5,34-35). «El Reino de Dios» designa, pues, el cósmico Reino de Padre o la creación sometida a su providente y universal Señorío, así como -y sobre todo- la celeste y eterna morada beatífica del Hijo y de los hijos (=justos) de Dios, sobre quienes el Padre reina.

\section{2) La presencia del Reino}

Ese doble «Reino de Dios» no es algo relegado meramente al futuro, sino también una realidad ya presente:

a) Aquél es, en efecto, el actual Reino cósmico de Dios o espacio creacional, donde desde «el principio» (Gén 1,1) del tiempo el Padre ejerce su dominio. Es lo que reiteradamente enseña Jesús, al afirmar que «el cielo es el trono de Dios» y «la tierra es el escabel de sus pies» (Mt 5,34 = Is 66,1a), precisando que su señorío no lo ejerce desde un mítico y lejano olimpo, pues «Jerusalén es la ciudad del gran Rey» (Mt 5,35= Sal 48,3b), quien, por lo demás, con providencia paterna «alimenta» a «las aves del cielo» $(\mathrm{Mt} \mathrm{6,26)}$ y «viste» a «los lirios del campo» (Mt 6,30) .... Toda la creación es ya Reino de Dios! En esta concepción enlaza Jesús ciertamente con la respectiva veterotestamentaria y judaica, como lo muestran por lo demás las implícitas referencias bíblicas de sus asertos, distanciándose de ambas, sin embargo, en la mencionada nnvedad teológica representada por su constante referencia del «Reino» te- 
rrestre al «Padre» celeste (Cf. supra): ¡Toda la tierra es ya dominio regio del Padre! Y de esta convicción brotó, incontenida, su primera bendición pública y exultante al Padre, invocándole como actual o efectivo «Señor del cielo y de la tierra» (Mt 11,25b=Lc 10,21b).

b) Jesús abrigó asimismo la convicción de que el Reino celeste del Padre es, en su fase terrestre, una inaugurada - no consumada - realidad. Sus mencionadas parábolas sobre «el Reino» (Cf. supra) no dejan lugar a duda: el paciente labrador «arroja» ya en la tierra la semilla; ya «está sembrando el diminuto «grano de mostaza» y «crece»; ya «el Hijo del Hombre» sembró «en el campo» del «mundo» la «buena semilla» de los «los hijos del Reino», junto a la que crece la por el diabólico «enemigo» previamente sembrada «zizaña» de «los hijos del maligno»; ya está echada «la red en el mar y recoge peces de todas clases»; la «levadura» ha sido metida «en tres medidas de harina»; envió el padre a sus dos hijos a laborar la viña, rehusándole el segundo (=los jefes del pueblo) la obediencia, que el primero (= publicanos y prostitutas) le rinde: ¡por eso les «preceden» éstos «en el Reino de Dios»! (Mt 21,31); las diez jóvenes participan ya del Reino, pues «salieron al encuentro del Esposo» mesiánico ${ }^{27}$, quien demora su definitivo ingreso en la sala del banquete nupcial precisamente por estar tratando sobre la dote de la esposa (Mt 25,1b.5a); en efecto, "ya está preparado» el banquete (Lc 14,17) nupcial (Mt 22,2.4b.8a) del «Reino de Dios»y, ante la excusa de los invitados (Lc 14,18-20=Mt $22,3 \mathrm{~b}-5)$, «el rey» (Mt) o simple anfitrión (Lc) ordena a sus criados llamar «a pobres y lisiados, ciegos y cojos» (Lc 14,21b)..., a cuantos - i «malos y buenos»! - encuentren (Mt 22,9-10) por «caminos y cercados» (Lc 14,23); éstos, devenidos discípulos de Jesús, son «los invitados» al nupcial banquete mesiánico del «Reino de Dios», con los cuales «está el Esposo» y quienes deben alegrarse - ino pueden ayunar!- «hasta que les sea quitado» (Mc 2,19-20)...¿Cómo pueden estar tristes los que, en la nupcial sala del Reino de Dios, gozan de la compañía del Esposo mesiánico ${ }^{28}$ y participan de la general alegría propia del festín del Reino?

Precisamente «los pobres» discípulos de Jesús son «bienaventurados» o felices por eso: «Porque de ellos es el Reino de Dios» (Lc 6,20=Mt 5,3), como lo es de los niños» (Mc 10,14par) y de quienes a ellos se asemejan (Mc

27. Tras la intel pretación escatológica de Mt 25,1-13 late sin duda una amonestación del Jesús histórico: Ch. H. Dodd, Parables, 137 (trad. españ., 164).

28. A la luz del trasfondo judaico sobre «la boda» como frecuente designación de «la era mesiánica» (Cf. STR.-BILL., I 517s.), pudo Jesús autodesignarse como «el (¿divino!) Esposo» mesiánico del nuevo Israel, integrado por la Comunidad escatológica de sus discípulos. Así con: V. TAYLOR, Mark ${ }^{2}$, 210s. (trad. españ., 234s); P. BonNARD, Matthieu, 133 (trad. españ., 209s); Cf. tambień: H. SchurmanN, Lukas, I 296; R. PESCH, Markus, I 173; y otros. 
10,15par), siendo ya también accesible no sólo a los convertidos «publicanos y prostitutas» (Cf. Mt 21,31) sino también a los «pobres y lisiados, ciegos y cojos», es decir, a los social y religiosamente desclasados y marginados, que aceptaron la invitación al mesiánico banquete del Reino (Lc 14,21) convirtiéndose y creyendo el mensaje de Jesús. ¡Todos esos forman la comunidad mesiánica del «resto de Israel»: Del ya presente «Reino de Dios» o «la Iglesia» de Jesús edificada sobre «la roca de Pedro (Mt 16,19) ${ }^{29}$; y ésta se identifica con la «pequeña grey» de sus discípulos, «los hijos del Reino» (Mt 13,38a), quienes al presente «nada deben temer, porque a su Padre le ha parecido bien darles el Reino» (Lc 12,32) ${ }^{30}$. El ingreso en él, del que «no está lejano» el escriba que interrogó a Jesús sobre «el primer precepto» de la Ley $($ Mc 12,34) y sí debe ser buscado por todos ( $\mathrm{Lc} 12,31=\mathrm{Mt} 6,33$ ), es obstaculizado «a los hombres» por los teólogos del judaísmo, pues «no entran ni dejan entrar a quienes están entrando» (Mt 23,13) en él: En «el presente» y «nuevo recinto de salvación» o "Comunidad del Reino» ${ }^{31}$. Aquellos entran, por lo demás, con la radical conducta de quienes, por causa del «Reinado de Dios», todo lo venden (Lc 18,18-26par) y lo dejan todo (Lc 9,59-62; 18,28-30par); con la valentía de quienes adquieren a todo precio «el Reino, (Mt 13,44-46), por cuyo ingreso practican «los mínimos preceptos de la Ley» $($ Mt 5,19) y «se hacen como niños» (Mc 10,15par) en la filial relación con Dios, su Pade; con la despiadada autoviolencia de quienes no dudan «cortar» y «arrancar» [sic] cuantos obstáculos impidan la conquista del «Reino» (Mc 9,43-47par): ¡Ésos son «los violentos», que «arrebatan el Reino de Dios», el cual «desde los días de Juan hasta ahora -durante el ministerio de Jesús- se abre paso con violencia»! (Mt $11,12)^{32}$.

Así formuló reiteradamente Jesús la por Él aquí en la tierra inaugurada realidad del futuro Reino celeste del Padre, integrado por quienes, conviertiéndose y aceptando su mensaje, le siguieron como «la pequeña grey» del nuevo Israel o la mesiánica Comunidad (= la Iglesia») de «los hijos del Rei-

29. Así con G.E. LADD, o.c., 242-57; J. CARmignaC, Mirage..., 48-49.96; Cf. también O. Cullmann, Petrus, Zürich-Stuttgart ${ }^{2} 1960,218-28$.

30. La autenticidad de ese «logion» ha sido demostrada por varios autores: W. PESCH, Zur Formgeschichte und Exegese von Lk 12,32, en: Bib 41 (1960) 25-40: 31-34; R. Pesch, «Sei getröst, kleine Herde» (Lk 12,32). Exegetische und eklesiologische Erwägungen, en: «Krise der Kirceh-Chancen des Glaubens. Die «kleine Herde» heute und morgen» (hrsg. von K. Faerber), Frankfurt 1968, 85-118: 94-102; J. JEREMIAS, $A b b a$, 43s; Theologie NT., 234 (trad. españ., 285); J. SCHLosser, o.c., 573-601: 579-89; para su análisis, Cf. también B.D. ChILTON, o.c., 231-50.

31. G.E. LADD, o.c., 119.192-93.

32. Así con: R. OtTo, o.c., 108ss; C.J. CAdoux, o.c., 130; T.W. MANSon, Sayings, 134s; E. Percy, o.c., 196s.; R. SchnACKenBuRG, Gottesherrschaft, 71-72.90 (trad. españ., 95.118s); G.E. LADD, o.c., 159s; B.D. ChILTON, o.c., 229s. 
no». Una concepción del todo extraña a la literatura veterotestamentaria y judaica, representando otra novedad teológica, que distingue y caracteriza el mensaje del Predicador e Inaugurador del «Reino de Dios».

\section{3) El futuro del Reino}

No se limita al presente, sin embargo, el horizonte del Reino. Éste, por el contrario, es a la vez una realidad futura. Propia, por lo demás, no sólo de su interno dinamismo hacia la plenitud sino también de su identificación con el escatológico recinto beatífico, cuyo ingreso es objeto de cercana y parusíaca esperanza:

a) El futuro cercano de la fase celeste del «Reino de Dios», en efecto, fue reiteradamente insinuado y enseñado por Jesús. Así ya en el contexto de su respuesta al joven rico (Mc 10.17-28par), quien le interrogó por lo que debía hacer "para heredar la Vida eterna» (v. 17par) y rehusando practicar el mandato del «Maestro bueno», - vender cuanto poseía, para tener «un tesoro en el cielo», y seguirle-, «se fue apenado, porque tenía muchos bienes» (vv. 2122par): "iMuy difícilmente los ricos entran en el Reino de Dios!», asegura seguida y reiteradamente Jesús a sus discípulos (vv. 23-25par), tranquilizando luego su angustioso interrogante sobre «¿quién podrá salvarse?» (v. 26par) con la consoladora respuesta: «Para Dios todo es posible!» (v. 27par). En este contexto, «el Reino de Dios» se identifica con la región beatífica del "cielo» ${ }^{33}$, cuyo cercano ingreso - iafecta a los discípulos! - asegura «la Vida eterna» o la «salvación» personal de cada hombre, "obtenida después de la muerte» ${ }^{34}$. Es lo que subraya también la grave prevención del Maestro a sus discípulos contra el escándalo infligido a «los pequeños, que creen en» Él (Mc 9,42-48 = Mt 18,6-9), exhortándoles a «cortar» y «arrancar» cuanto les pueda arrojar «en la gehenna» y obstaculizar su ingreso en «la Vida» (Mc 9,43= Mt 18,8) o «en el Reino de Dios» (Mc 9,9,47= Mt 18,9: «La Vida»). También en este contexto «el Reino» es sinónimo del beatífico recinto de «la Vida» eterna, en contraposición a la horrible región de «la gehenna», cuyo posible ingreso -ide los discípulos! - en una u otra se reserva para el indeterminado pero, en todo caso, cercano momento, «que sigue a la muerte» ${ }^{35}$. Análogo significado

33. M.-J. Lagrange, Marc, 268.

34. Así con J. CARMignac, Mirage..., 33; Cf. también M.-J. Lagrange, loc. cit.; Id., Matthieu, 379s.

35. M.-J. Lagrange, Marc, 251; Cf. también J. Carmignac, Mirage..., 31.

36. Cf. J. Carmignac, Mirage..., 44. Ambos textos reflejan, sin duda, la redacción literaria e interpretación teológica de Mateo (Cf. G. BARTH, Das Gesetzverständnis des Evangelisten Matthäus, en: "Überlieferung und Auslegung im Matthăus-Evangelium» [WMANT, 1], Neukirchen-Vluyn 41965, 54-154: 60.68s; G. STRECKER, Der Weg der Gerechtigkeit [FRLANT, 82], 
envuelve «Basileia» en la promesa del Maestro a sus discípulos sobre el ingreso en «el Reino» (Mt 5,20; 7,21), condicionándo éste a su actual superación de la «justicia» judaica (Mt 5,20) en el fiel cumplimiento de la voluntad del $\mathrm{Pa}$ dre (Mt 7,21) ${ }^{36}$ : ¡Corren el riesgo de ser excluidos! Es lo que, con sin igual dramatismo, les enseña en la parábola de la diez vírgenes (Mt 25,1-13), tras cuya teológica interpretación del evangelista Mateo sobre la necesidad de esperar vigilantes y con las «encendidas antorchas» de las «buenas obras» (Cf. Mt 5,14-16) el ignorado momento del parusíaco retorno del Esposo celeste ${ }^{37}$, late sin duda un núcleo histórico: El de la parábola sobre «una boda real» ${ }^{38}$, en la que los discípulos son exhortados seriamente a estar preparados para el ignorado pero, en todo caso, cercano momento del ingreso en «el Reino» ${ }^{39}$. Una concepción análoga refleja el «logion» de Jesús sobre la participación de las naciones paganas en el banquete del «Reino de Dios» (Lc 13,28s $=\mathrm{Mt}$ 8,11 s) ${ }^{40}$, del que serán excluidos «los hijos del Reino» (Mt 8,12), es decir, los judíos («vosotros»: Lc 13,28b): Afirmación inaudita ciertamente para oídos judaicos, pero en total asonancia con el mensaje de quien, re-asumiendo profecías sobre la conversión de las naciones (Is 49,12) y su participación en el banquete escatológico (Is 25,5-6), excluye a los incrédulos en su mensaje y promete a quienes lo aceptan (Cf. Lc 14,15-24par) el cercano gozo del Reino, que seguirá a la muerte («veréis»: Lc 13,28b) de unos y otros ${ }^{41}$. A ese no lejano Reino celeste se refiere asimismo Jesús, cuando, durante la última cena pascual, asegura a sus discípulos no comer más «la pascua» con ellos «hasta que -idespués de su resurrección! - se cumpla en el Reino de Dios» (Lc

Göttingen ${ }^{2} 1966,151$ s). El evangelista, sin embargo, trabajó sobre material tradicional: Si el verbo «perisséuein» no es característico de su vocabulario (= Mt 5 x Mc 1 x Lc 4 x) y la fórmula introductoria «légo hymîn» sí es característica del lenguaje de Jesús (Cf. H. SchứmanN, Die Sprache des Christus, en: BZ 2 [1958] 54084: 61.71), en Mt 7,21 la invocación «Señor, Señor» es preredaccional (Cf. par. Lc 6,46), siendo la designación «mi Padre» propia del Jesús histórico, a quien puede remontarse asimismo la construcción (- $i \sin$ analogía en el judaísmo y rara en el NT!-) «entrar en el Reino»: Cf. J. JeREMIAS, Theologie NT, 41 (trad. españ., 48).

37. Cf. J. JEREMIAS, Gleichnisse, 48s (trad. españ., 64s).

38. J. JEREMIAS, Gleichnisse, 49,171-74 (trad. españ., 65,210-13).

39. Puesto que la exhortación de Jesús afecta directamente a sus discípulos, la parábola no se refiere a "la crisis escatológica inminente» de la consumación final» (J. JEREMIAS, Gleichnisse, 50,175: trad. españ., 66.214): Las imágenes de la «media noche» y «el sueño», el ingreso en el banquete» y el cierre de «la puerta» muestran, más bien, que se trata de la exhortación para el «futuro relativamente cercano» J. CARMIGNAC, Mirage..., 55) del ingreso en el Reino tras la muerte.

40. Un detallado análisis ofrecen: B.D. ChILton, o.c., 197-201; J. SCHLOSSER, o.c., 603669; Cf. también J. Jeremias, Jesu Verheissung für die Völker, Stuttgart ${ }^{2} 1959,47-54$; Id., Theologie NT, 236s. (trad. españ., 287).

41. Así con: M.-E. BoISMARd, Sinopsis de los cuatro Evangelios, II (trad. españ.), Bilbao 1977, 270; J. Carmignac, Mirage..., 41; W. Grundmann, Lukas, 286. 
$22,16){ }^{42}$, ni beber «del zumo de la vid hasta el día en que - itras su resurrección! - lo bebe nuevo en el Reino de Dios» (Mc 14,25), su Padre (par.Mt 26,29), tranquilizándoles con la consoladora promesa de disponer para ellos «el Reino», que el Padre le dispuso, donde participarán con Él del gozo celeste y juzgarán luego «a las doce tribus de Israel» (Lc 22,29-30).

En todos estos textos, «el Reino de Dios» se identifica por tanto con «el cielo» o «la Vida eterna», es decir, con el celeste Reino del Padre, cuyo ingreso es prometido para el cercano momento que sigue a la muerte.

b) No menor interés ofrece la enseñanza de Jesús sobre el futuro lejano propio de la fase celeste del «Reino de Dios», reiteradamente insinuado en varias de sus mencionadas parábolas: $\mathrm{Si}$ «la semilla» sembrada por el paciente labrador «germina y crece» desde el tierno tallo hasta «la espiga con abundante trigo» (Mc 4,27s), también el grano de mostaza «crece» hasta que «a la sombra» de sus «grandes ramas» aniden «los pájaros del cielo» (Mc 4,32par): Las naciones paganas; de modo análogo actúa la levadura en la masa de harina «hasta que la fermentó toda» (Mt 13,33b=Lc 13,21)... ¡Así describió Jesús no sólo el evidente contraste entre el insignificante principio y el grandioso final del «Reino de Dios», -identificado con la diminuta Comunidad de sus discípulos-, sino también el incontenible dinamismo interno del mismo, que garantiza y asegura esa ciertamente remota pero, en todo caso segura plenitud universal. Este aspecto universal del Reino futuro ${ }^{43}$ es subrayado por otras parábolas: En «el campo» del «mundo», identificado éste con «el Reino de Dios» (Cf. Mt 13,24.38) y del «Hijo del hombre» (Cf. Mt 13,37-41), la «buena semilla» de «los hijos del Reino» y «la zizaña» de «los hijos del maligno» deben crecer «juntos hasta «la siega» o «el fin del mundo» (Mt 13,30a.39b), como la pesca de «toda clase de peces» dura mientras la red no «está llena» (Mt 13,47s); asimismo, tanto las vírgenes prudentes como las necias deben estar preparadas con «el aceite» del amor (Cf. Cant 1,3; Prov 27,9; Sal 133,1-2) o del Espíritu (Cf. Is 61,1) hasta que llegue el mesiánico Esposo (Mt 25,2-12), como «los siervos» tienen que comerciar con los «talentos» o dones recibidos

42. Cf. H. SchUrmann, Der Paschamahlbericht. Lk 22, (7-14) 15-18 (Neutestam. Abh., XIX. 5), Münster 1968, 1-74: Los vv. 15-18 reflejan una tradición pre-lucana'(14-23). Y en el contexto de la misma la «Basileia» designa no «el Reinado» sino «el Reino de Dios» (H. SCHURMANN, o.c., 51; J. CARmignac, Mirage..., 62) o la «Vida celeste», en la que Jesús entrará después de la Resurrección: J. CARMignac, loc. cit., P. Schanz, lukas, 504; así también M.-J. Lagrange, Luc 542 ("...l'éternité bienhereuse après la résurrection»).

43. Muy bien acentuado por varios autores: J. JEREMIAs, Gleichnisse,-145-53: 152s (trad. españ., 179-88: 187s); J. Becker, o.c., 208s; M. Dibelius, Jesus, 54s; S. LeON-Dufour, Les Évangiles..., 388-90 (trad. españ., 343s); R. SCHNACKENBURG, Gottesherrschaft, 98-109: 109 (trad. españ., 129-44: 143s); G.E. LAND, o.c., 230-34. 
para la evangelización (Cf. Lc 9,1-2par; 10,9) hasta la vuelta de «su Señor» (Mt 25,14ss); pues la invitación al nupcial banquete del Reino no cesa hasta que «se llene» toda «la sala» (Mt) o «la casa» (Lc) de cuantos invitados — «malos y buenos» (Mt) — acepten la llamada (Lc 14,21-24 = Mt 22,9-10)...

La por Jesús inaugurada fase terrestre del «Reino de Dios» dura, por tanto, hasta el lejano futuro de la universal plenitud consumada en su fase celeste: Mientras la mesiánica Comunidad de sus discípulos no cumpla su salvífica misión de «salar la tierra» e «iluminar al mundo» (Mt 5,13-16); hasta que a todos los hombres llegue la posibilidad de devenir «hijos del Reino» 0 «hijos del maligno», de aceptar o rechazar la invitación al banquete mesiánico; pues i «todos son llamados» a entrar en la fase terrestre del Reino, «pero pocos (son) los escogidos» para el cercano y parusíaco ingreso en la fase celeste del mismo! (Mt 22,14).

c) Sobre el futuro parusiaco, inherente a la fase celeste del «Reino de Dios» nos informan las parábolas de la zizaña (Mt 13,24-30.36-43) y de la pesca (Mt 13,47-50), pronunciadas probablemente por Jesús como enérgica respuesta a quienes - fariseos o discípulos procedentes del fariseísmo- le urgían la selección del «resto santo» de Israel: ¡No!, respondió el Maestro, isólo al final serán separados los peces buenos de los malos (Mt 13,49s); isólo «al tiempo de la siega» será separada la zizaña del trigo, cuando "al fin del mundo» serán «los hijos del maligno» arrojados «al horno del fuego» eterno y «los hijos del Reino» brillarán "como el sol en el Reino de su Padre» (Mt 13, 39b-43) ${ }^{44}$. A esa parusíaca separación se refiere Jesús asimismo en su dramática descripción sobre el juicio final (Mt 25,31-46). Al nivel de la redacción mateana, «todas las naciones» (v. 32a), a las que previamente fue predicado «el evangelio del Reino» (Mt 24,14; Cf. 28,19), serán juzgadas por el mesiánico y glorificado «Hijo del hombre» (v. 31), otorgando «el Reino» eterno del Padre (v. 34) o la «Vida eterna» (v. 46b) y castigando con «el fuego eterno» (vv. 41-46a) a quienes le hayan benificado (vv. 35-39) o abandonado (vv. 4244), respectivamente, en la persona de «sus hermanos más pequeños» (vv. 40.45) o discípulos (Cf. Mt 12,49s; 18,1-5), con quienes Él se identifica (Cf Mt $10,40 ; 18,5)$.

La fase celeste del parusíaco «Reino de Dios» se identifica, por tanto, con el eterno (Mt 25,34) «Reino del Padre» (Mt 13,43; 25,34) o la morada de los justos en la «Vida eterna» (Mt 25,46b).

44. Así con: J. Jeremias, Gleichnisse, 221-24 (trad. españ., 269-74); Id., $A b b a$, 129-31: 130s; Id., Theologie NT, 173s (trad. españ., 209s); Cf. también R. SCHNACKENBURG, Gottesherrschaft, 107-9 (trad. españ., 141-43); G.E. LAdD, o.c., 237; J. CARMignaC, Mirage..., 45s. 47. 


\section{2. «El Reinado de Dios»}

De todos los textos, en los que «Basileia» designa «el Reinado de Dis» ${ }^{45}$, unos se refieren a la cercanía del mismo, anunciada tanto por Jesús (Mc 1,1415par) como por sus enviados (Mt 10,7 [Cf. Lc 9,2]; Lc 10,9.11); otros señalan su presencia (Cf. Lc 17,21), realizada mediante la palabra (Mc 4,3-11.1320par) y exorcismos (Lc 11,20=Mt 12,28) de Jesús; algunos, finalmente, preveen su venida futura (Mc 9,1 par; Lc 11,2= Mt 6,10). Todos ellos, sin embargo, designan una cosa:

\section{1) El Reinado del Padre}

Que Dios es Rey eterno y ejerce su Reinado tanto sobre la creación como -y especialmente- sobre Israel, es una concepción heredada por Jesús de su tradición veterotestamentaria y judaica. La absoluta novedad teológica de su mensaje al respecto consiste precisamente en su constante referencia del «Reino de Dios» al «Padre». Esto, efectivamente, insinúan ya los textos en que, explícita o implícitamente, Jesús habla del «Reino» o recinto, donde -el universo, la Comunidad mesiánica, la celeste morada beatífica- el Padre ejerce su Señorío (cf. supra). Por lo demás, la parábola sobre el siervo despiadado (Mt 18,23-35) no deja lugar a duda: Mediante el proceder de «un rey» (v. 23b) o «señor» (vv. 25.27.32.34) quien, «movido a compasión», condonó a uno de sus siervos la grande e insaldable deuda (v. 27) y, tras la despiadada conducta de aquél para con uno de sus colegas (vv. 28-30), ordenó, «encolerizado», encarcelarle «hasta pagar cuanto le debía» (v. 34), describió Jesús «el Reino de Dios» (v. 23a) o la actitud de su «Padre celeste» para con aquellos de sus discípulos, que «no perdonan de corazón a sus hermanos» (v. 35). ¡El padre es esencialmente Rey! Y tanto su gratuito perdón inicial como su severo castigo son dos formas de ejercer su Reinado (cf. infra). A él se refiere asimismo la oración de los discípulos, cuando, tras invocar al «Padre» y rogarle por la santificación de $s u$ «Nombre», le suplican que «venga su Reinado» (Cf. infra). Esos son los dos únicos textos, en que «el Reinado de Dios» está explícitamente relacionado con «el Padre». ¿Un testimonio ciertamente exiguo! No el único, sin embargo. A él se suma el implícito en los múltiples textos sobre «el Reino del Padre» (Cf. supra). Por lo demás, ¿no se refirió Jesús al «Padre» siempre que habló de «Dios»? Todo ello muestra, que Él se refirió asimismo al «Reinado del Padre» aún cuando habló del «Reinado de Dios». Y lo hizo frecuentemente. Ante todo, para proclamar su cercanía:

45. Cf. supra, n. 22 . 
2) « Se acercó el Reinado de Dios!»

El evangelista Marcos introduce el público ministerio galilaico de Jesús con su anuncio: «iSe ha cumplido el tiempo y está cercano el Reinado de Dios, convertíos y creed en la Buena noticia!» $(\mathrm{Mc} 1,14=\mathrm{Mt} 4,17){ }^{46}$. Ese anuncio se remonta sustancialmente al Jesús histórico ${ }^{47}$, quien, tras su mesiánica vocación (Mc 1,9-11 par) y victoria sobre el diabólico «tentador» (Mt 4,1-11par) o señor de «todos los reinos del mundo» (Mt 4,8-9= Lc 4,5-6), inició su actividad mesiánica con la solemne proclamación: «Dios ha colmado» plena y definitivamente (=peplérotai) «el tiempo» de la manifestación tanto de su Reinado como del Mesías (= ho kairós), «estando ya por tanto muy cercano (=kaí éggiken) el Reinado de Dios» o su Señorío (= he basileia toû Theoû) sobre el mundo y los hombres, antes sujetos uno y otros a la tiranía del diabólico señor (cf. supra): «iConvertíos y creed en la Buena Noticia» de este anuncio! Estas últimas - conversión y fe- son las dos exigencias, para ser librados de aquella tiranía y aceptar el cercano Señorío de Dios, por Jesús ya desde el principio proclamado y por Él seguidamente inaugurado, mediante su palabra y exorcismos (cf. infra).

Idéntico anuncio envuelve la predicación inicial de sus discípulos, por Él enviados «a las ovejas perdidas de la casa de Israel» (Mt 10,6) sin más seguridad humana (Cf. Mc 6,8-9par) que la previamente conferida potestad tanto "sobre los espíritus inmundos» como sobre «toda clase de enfermedades» (Mt 10,1 par; Cf. 10,8; Lc 10.9a), para proclamarles con credibilidad «la inminente cercanía del Reinado de Dios» (Mt 10,7 ;Lc 10,9.11) y exhortarles a convertirse $(\mathrm{Mc} 6,12)$. Por lo demás, esa misión de los discípulos tiene por finalidad preparar el ministerio mesiánico del Maestro (Cf. Lc 10.1). En este sentido, sus exorcismos y curaciones anuncian - como signos - el muy cercano fin de la tiranía diabólica, corroborando por tanto su proclamación sobre la inminente cercanía del Señorío de Dios, seguidamente inaugurado por Jesús mediante su poderosa palabra y obras salvíficas.

\section{3) «زAquí está el Reinado de Dios!»}

A los fariseos, que le interrogaban por el momento de la manifestación del «Reinado de Dios» (Lc 17,20a), respondió Jesús, que éste se resiste a todo

46. Para su análisis, Cf. especialmente: R.H. Fuller, Mission, 21-25; V. TAYLOR, Mark ${ }^{2}$, 166s (trad. españ., 181s); F. MUSSNER, art. cit., 86-90; R. MERKLeIN, o.c., 17-20.31-35; W.H. Kelber, o.c., 3-15; R. Pesch, Markus, I 101-108 (bibliogr.); B.D. Chilton, o.c., 27-95, espec., 65ss; J. SCHLOSSER, o.c., 91-126: 98ss.

47. Cf. R. Merklein, o.c., 31-35; R. Pesch, o.c., I 101-104. 
cálculo temporal y local (Cf. Lc 17,20b-21a), «pues - prosigue- el Reinado de Dios está entre vosotros» (Lc 17,21b). Con esta última afirmación, que constituye una de las más célebres «crux interpretum» de la exégesis evangélica y cuya autenticidad sustancial no puede ponerse en duda ${ }^{48}$, Jesús afirma sin ambages, que «el Reinado de Dios está presente» ${ }^{49}$ no en el interior de sus oyentes sino «en medio de» ellos ${ }^{50}$. ¿En qué sentido? Sin duda, en su misma persona. Pero no sólo en ella:

a) Según el evangelista Lucas, tras su inicial ministerio galilaico (Lc 4,14s) Jesús se dirigió a Nazaret, donde, «según su costumbre», asistió «el día del sábado» al culto sinagogal ( $\mathrm{Lc} 4,16 \mathrm{a}$ ), leyendo y auto-aplicándose en esa ocasión (cf. Lc 4,16b-21) el oráculo isaiano (Is 61,1-2a) sobre el Mensajero escatológico, «ungido» por «el Espíritu del Señor» y por Él «enviado a proclamar a los pobres la Buena Noticia, a proclamar la liberación a los cautivos y la recuperación de la vista a los ciegos, a poner en libertad a los oprimidos y a proclamar un año de gracia del Señor» (Lc 4,18-19) ${ }^{51}$. Este anuncio de «la Buena Noticia a los pobres» ocupó un puesto central en su actividad mesiánicá. Con él culmina, en efecto, su respuesta al interrogante del encarcelado Juan sobre si se identificaba con «el que había de venir» (Mt 11,3=Lc 7,19), actualizando asimismo varios oráculos isaianos sobre los signos de la salvación mesiánica (Is 26,$19 ; 29,18 \mathrm{~s} ; 35,5 \mathrm{~s} ; 61,1$ ) y remitiendo a lo que los enviados de Juan «oyeron y vieron» durante su ministerio:

«Los ciegos ven de nuevo y los cojos andan, los leprosos son purificados y los sordos oyen, los muertos resucitan y a los pobres se les anuncia la Buena Noticia, ¡y feliz es quien no se escandaliza en mí» ${ }^{52}$.

Si sus milagros son, pues, esencialmente, gestas salvíficas de la preanunciada salvación mesiánica (Cf. infra), su predicación actualiza también la

48. Cf. R. Bultmann, SynopTrad.; 24; M. Dibelius, Formgeschichte, 162; N. Perrin, Rediscovering, 72s; y otros, entre los cuales últimamente J. SCHLOSSER, o.c., 181-88.

49. Así con: T.W. MAnson, Sayings, 304s; R. OTto, o.c., 131-37; W.G. KÜMMEL, Verheissung, 28s; N. PERRIN, Kingdom, 175s; Id., Rediscovering, 74; Id., Language, 43-46; R. SCHNACKENBURG, Gottesherrschaft, 93s (trad. españ., 122s); G.E. LADD, o.c., 224, n. 25; J. CARMIGNAC, Mirage..., 59s; J. ScHLOSSER, o.c., 212-15.

50. Así con T.W. Manson, o.c., 304; W.G. Kúmmel, Verheissung, 27s; N. Perrin, Kingdom, 175s; Id., Rediscovering, 73s; J. CARMIGNAC, Mirage..., 59; J. SCHLOSSER, o.c., 203-208; Cfr. también: R. Bultmann, SynopTrad., 128; Id., Theologie NT, 5 (trad. españ., Salamanca 1981, 45).

51. Tras la redacción lucana de Lc 4,16-21 late una tradición de toda probabilidad histórica: Cf. S. SABugal, La embajada mesiánica de Juan Bautista, Madrid 1980, 168, n. 165; B.D. Chilton, o.c., 123-77: 157ss.

52. Para su análisis, Cf. S. SAbugal, La embajada mesiánica..., 29-202: 141 ss. 
prometida Buena Nueva a los pobres ${ }^{53}$. ¿Cuál exactamente? A esta pregunta responde el mencionado trasfondo isaiano, completado por el respectivo oráculo sobre el escatológico «Mensajero ... de la Buena Nueva, que anuncia la salvación y dice a Sión: ¡Ya reina tu Dios!» (Is 52,7) ${ }^{54}$. La Buena Noticia, proclamada por Jesús a los pobres, consiste por tanto en la presencia del Reinado de Dios, inaugurado ya por su palabra. Ésta es «nueva» (Mc 1,27 = Lc $4,36)$ y «poderosa» (Cf. Mc 1,22par) precisamente porque, pronunciada a impulso del «Espíritu del Señor» (Cf. supra), es esencialmente una palabra pneumática, capaz por tanto de «inaugurar la nueva era» y realizar «los signos del cumplimiento mesiánico» e «introducir el Reinado de Dios» ${ }^{55}$. Es lo que afirma la parábola del sembrador (Mc 4,3-23par) sobre «el misterio del Reinado de Dios» (Mc 4,11par) o la ya secretamente inaugurada realidad de su presencia, antes de su manifestación apocalíptica ${ }^{56}$ : Si es cierto que «la palabra del Reinado» de Dios (Mt 13,19) no fructifica en tres cuartas partes de sus oyentes (Cf. Mc 4,4-7.19-22par), isí produce plenitud escatológica en «la tierra buena» de quienes «la oyen y entienden»! (Cf. Mc 4,8.23par). En éstos - sólo en ellos - la semilla de la palabra germina secreta y poderosamente con la fuerza del Espíritu (Cf Jn 6,63; 3,34), liberándoles tanto del pecado (Cf. Jn $8,31-36)$ como de toda opresión diabólica (Cf. Lc 13,16) y dándoles con ello la posibilidad de abrirse al Reinado de Dios.

b) Signos sacramentales del, mediante la palabra, proclamado e inaugurado Señorío de Dios son precisamente los milagros y exorcismos de Jesús ${ }^{57}$.

Ningún texto evangélico, es cierto, relaciona expresamente sus milagros

53. Cf. S. Sabugal, La embajada mesiánica..., 178-91. Así también: Ch. H. Dodd, Parables, 31-33.35 (trad. españ., 53-55.57); W.G. KUMMEL, Verheissung. 102-104; Id., Theologie NT, 32s; X LeOn-Dufour, Les Évangiles, 380 (trad. españ., 336); R. ScHnackenBurg, Gottesherrschaft, 81s (trad. españ., 106-108); J. JEREMIAS, Gleichnisse, 115s. (trad. españ., 144s); Id., Theologie NT, 106s (trad. españ., 127s); J. CARMIGNAC, Mirage..., 37; J. SchlossER, o:c., 155-78; 162-64. Sobre la autenticidad histórica de Mt 11,2-6 (= Lc 7,18-23), Cf. S. SABuGAL, o.c., 141170.

54. Las figuras del «Ungido» (Is 61,1) y del «Mensajero» (Is 52,7) fueron interpretadas mesiánicamente por el judaísmo contemporáneo (=11QMelch 16.18) a Jesús: Cf. S. SABugAL, o.c., 176.189; G. FRIEDRICH, art. euaggelizomai, en: ThWNT, II 714-18: 713s.

55. G. FRIEDRICH, art. cit., 715; Cf. también: E. BAMMEL, art. ptochós, en: ThWNT, VI * 888-915: 903; G.E. LADD, o.c., 161s.

56. Así con G.E. LADD, o.c., 417-25: 418.421; Cfr. también J. JEREMIAS, Gleichnisse, 1214.227 (trad. españ., 19-22.277). En la situación histórica de esa parábola, Jesús subraya el dinamismo ínsito en «la Palabra del Reinado de Dios», para producir abundante fruto en quienes la acogen. Así con: G.E. LADD, o.c., 226; J. CARMignac, Mirage..., 27s.

57. Cf.: A. RichaRdSON, The miracles-stories of the Gospels, London 1941, 45-50 (trad. españ., Madrid 1974, 58-64); W.G. KUMMEL, Verheissung, 98-114; R. SCHNACKENBURG, Gottesherrschaft, 79-88 (trad. españ., 105-116); G.E. LADD, o.c., 135-150; F. MuSSNER, Die Wunder Jesu, München 1967, 45-53 (trad. españ., Estella 1970, 36-42); J. JEREMIAS, Theologie NT, 89-99 (trad. españ., 107-119); S. SABUGAL, o.c., 170-91. 
con aquel Reinado. Y, sin embargo, esa relación es esencial. El trasfondo isaiano tanto de su inicial predicación en Nazaret como de su respuesta al interrogante de Juan (Cf. supra) muestra claramente, en efecto, que los milagros de Jesús actualizan los preanunciados signos de la salvación mesiánica (Is 26,$19 ; 29,18 ; 35,5 \mathrm{~s} ; 61,1 \mathrm{~s}$ ) sobre la curación de ciegos y sordos (Is 29,$18 ; 35,5$; 61,1 ), cojos y mudos (Is 35,6 ), así como la resurrección de los muertos (Is 26,19). Aquella proclamación era, pues, realmente una «Buena Noticia», la que «anuncia la salvación y dice a Sión: ¡Ya reina tu Dios!» (Is 52,7). Este Reinado inaugura, por tanto, los milagros de Jesús, al actualizar los signos del mismo (Mt 11,5 = Lc 7,22) y hacer ostensible la en ellos pre-anunciada salvación mesiánica, en calidad de gestas salvíficas, que traducen en actos y corroboran la «Buena Noticia» sobre la presencialización del «Reinado de Dios». Aquéllos son fundamentalmente, por tanto, actos victoriosos sobre toda realidad de sufrimiento (= «ciegos ven, cojos andan...») y de muerte (= «muertos resucitan»), gestas liberadoras de la opresión satánica (Cf. Lc 13,10-16) y, consiguientemente, signos del ya presente Señorío de Dios ${ }^{58}$.

Esa inauguración realiza asimismo $-\mathrm{y}$ sobre todo- los exorcismos de Jesús ${ }^{59}$. Así los interpretó Él mismo, respondiendo a quienes los atribuían a un arte diabólico (Mc 3,22par): ¡Si Satanás arroja a Satanás, significa que su «reino está dividido» y, por tanto, «no puede subsistir»! (Mc 3,23-26par); «pero si yo arrojo los demonios con el dedo ( $M t$ : el Espíritu) de Dios, ¡ entonces es que llegó sobre vosotros el Reinado de Dios!» (Lc 11,20=Mt 12,28), tras haber sido aquél atado por «el más fuerte», para saquearle «su casa» (Mc 3,21-22par). Sus exorcismos fueron, pues, considerados por Él como un saqueo de «su casa» y una destrucción de «su reino», el inicio de la lucha escatológica o guerra santa contra el diabólico «enemigo» del Reinado de Dios ${ }^{60}$

58. Así con: R. SCHNACKEnBURG, Gottesherrschaft, 82 (trad. españ., 108); F. MuSSNER, o.c., 52 (trad. españ., 38).

59. Cf. W.G. Kummel, Verheissung, 98-102; X. Leon-Dufour, Les Évangiles, 380-82 (trad., españ., 336s); R. SCHNACKENBURG, Gottesherrschaft, 84-87 (trad. españ., 110-113); G.E. LADD, o.c., 145-54; C.K. BARRETT, The Holy Spirit in the Gospel Tradition, London 1966, 62-68; J. JeREmias, Theologie NT, 96-99 (trad. españ., 115-19); Th. LoRENZMEIER, Zum Logion Mt $12,28=L k 11,20$, en: «Neues Testament und christliche Existenz» (Fs. H. Braun), Mainz 1973, 289-304; J.D.G. DunN, Jesus and the Spirit, London 1975, 44-53; P. GRELOT, Les miracles de Jésus et la demonologie juive, en: «Les miracles de Jésus selon le Nouveau Testament» (ed. X. Léon-Dufour), Paris 1977, 59-72: 64-67.70; S. SABUGAL, La embajada mesiánica, 254-57 (con bibliografía críticamente valorada); A. FEUILLET, art. cit. (DBS, X) 71-73.

60. Un aspecto subrayado por la mayor parte de los autores: Cf. O. BETZ, Jesu heiliger Krieg, en: NT 2 (1958) 116-37; 125ss.; N. PERRIN, Kingdom, 171; Id., Rediscovering, 67; J. BECKER, Das Heil Gottes, 209-213; G.E. LADD, o.c., 146s; R. SCHNACKENBURG, Gottesherrschaft, 85s (trad. españ., 112s); J. Jeremias, Theologie NT, 96-99 (trad. españ., 117-19); S. SABUGAL, La embajada mesiánica, 254. Una concepción particularmente resaltada por el evangelista Marcos: Cf. O. BAUERFEIND, Die Worte der Dämonen im Markusevangelium (BWANT, 8), Stuttgart 1927, espec., 6-28; W. KELBER, o.c., 15-18. 
...jLa revolución mesiánica! Todo ello, por lo demás, realizado «con el dedo de Dios» (Lc 11,20=Ex 8,15) o la fuerza del Espíritu (Mt 12,28), es decir, con el mismo poder usado por Moisés en la realización de las gestas salvíficas del éxodo: Los exorcismos de Jesús inauguran, por tanto, el «nuevo éxodo» mesiánico ${ }^{61}$, liberando al nuevo Israel de la tiranía impuesta por el «faraón» diabólico, siendo también signos de que, derrocado el señorío de Satanás y aniquilado su «reino», los por él oprimidos quedan libres para aceptar el Señorío de Dios ${ }^{62}$. Aquellas gestas liberadoras muestran, por tanto, no a la cercanía del Reinado de Dios sino su inauguración o presencia: « $i \mathrm{Ha}$ llegado!» ${ }^{63}$.

Podemos, pues sintetizar los precedentes desarrollos, afirmando que la inaugural llegada del Reinado de Dios fue realizada por Jesús no sólo con la misma presencia de su persona sino también mediante su palabra y milagros así como -y sobre todo- mediante sus exorcismos. Y esto constituyó precisamente su Buena Noticia: ;Llegó para todo hombre oprimido por el diablo el fin del señorío de Satanás, derribado «del cielo como un rayo« $(\operatorname{Lc} 10,18)$; ¿Llegó la pre-anunciada «liberación de los cautivos» con el don de «la libertad a los oprimidos!» (Lc 4,18-Is 61,1); ;llegó el «año de gracia del Señor» (Lc $4,19=$ Is 61,2a), el gran perdón, con la inauguración de su Señorío!; ; ha llegado el Reinado de Dios! Pero, subrayémoslo, sólo inauguralmente: no en su plenitud final. Pues el mismo Jesús enseñó a sus discípulos suplicar al Padre:

\section{4) «j Venga tu Reinado!»}

La relación del «Reinado de Dios» con el verbo «venir» (Lc 11,2 [ = Mt $6,10] 17,20 ; 22,18 ;$ Mc 9,1) es ignorada por la literatura veterotestamentaria y judaica así como por la extra-evangélica literatura neotestamentaria. Aquella relación fue, pues, característica de Jesús. Lo que no significa, que en todos los mencionados textos se remonte a sus palabras. Al contrario. Esos muestran ya una acusada preferencia de ella por Lucas, a cuya redacción pertenece

61. Así con N. Perrin, Rediscovering, 66s.

62. Así con G.E. LADD, o.c., 148.

63. Así con: J. Weis, o.c., 88ss; G. Dalman, o.c., 88; R. OtTo, o.c., 101-105; Ch. H. Dodd, art. cit., 138ss; Id., Parables, 28-29.35 (trad. españ., 50-51.57); T.W. MANSON, Teaching., 82s; W.G. KuMmEL, Verheissung. 98-102: 99s; Id., Theologie NT, 33; H.E. TODT, o.c., 237-40; X. Leon-Dufour, Les Évangiles..., 381 (trad. españ., 336s); N. Perrin, Kingdom, 171.173; Id., Rediscovering, 63-67; J. BECKER, o.c., 201.209-11; R. SCHNACKENBURG, Gottesherrschaft, 84s (trad. españ., 110s); H. Flender, o.c., 48; G.E. LADD, o.c., 139-41; J. JerEMIAS, Gleichnisse, 122s (trad. españ., 152); Id., Theologie NT, 98 (trad. españ., 118); H. MERKLEIN, o.c., 158-60; J. SCHLOSSER, o.c., 127-53: 134-39. 
claramente Lc 22,18 (par. Mc 14,25) ${ }^{64}$. Una tradición histórica recoge, por el contrario, los otros dos textos:

a) $L c 17,20 b$ reproduce la respuesta de Jesús a los fariseos sobre «cuándo vendrá el Reinado de Dios» (v. 20a), afirmando que éste «viene sin dejarse sentir» (v. 20b): ¡No se puede determinar mediante presagios o síntomas (= «paratéresis») el momento de su venida! La cual, por lo demás, tampoco es localizable en un «aquí o allá» (v. 21a) determinado, «pues el Reinado de Dios está entre vosotros» (v. 21b) ya: Sin duda, mediante sus palabras y gestas sálvíficas (cf. supra). Éstas inauguran, por tanto, la venida del Reinado de Dios.

b) $M c 9,1$ anuncia, por el contrario, una futura venida de aquel «Reinado». Tras la instrucción de Jesús «a la multitud junto con sus discípulos» sobre las condiciones para seguirle (Mc 8,34-38par), y antes de trasfigurarse (Mc 9,2-8par) ante «Pedro, Santiago y Juan» (v. 2par), el Maestro aseguró «que algunos de los aquí presentes no probarán la muerte, hasta que vean el Reinado de Dios venido con poder» (Mc 9,1). Los paralelos de Mt 16,28 y Lc 9,27 son sin duda interpretaciones de su fuente marciana, la cual nos trasmitió una «antiquísima palabra» de Jesús ${ }^{65}$. ¿Qué significa, exactamente? Los «algunos aquí presentes», que «verán el Reinado de Dios» (Mc 9,1=Lc 9,27) son con toda probabilidad los tres mencionados discípulos, «antes quienes» se transfiguró Jesús (Mc 9,2b=Mt 17,2a) y quienes «vieron su gloria» (Lc 9,32b), de modo que, concluida la jesufanía, ya «no vieron a nadie sino sólo a Jesús con ellos» (Mc 9,8=Mt 17,8). ¿Qué vieron antes? Lucas es del todo explícito: i Su gloria»! Los tres discípulos vieron la anticipada «gloria» del Resucitado (Cf. Lc 24,26), por la que los vestidos del Transfigurado devinieron «de una blancura fulgurante» (Lc 9,29b; Cf. 24;4). Esta concepción lucana late asimismo en los relatos de Mateo y Marcos: Quien, tras su resurrección, «se manifestó en otra forma (en hetéra morphé) a dos» discípulos (Mc 16,12), fue Él mismo que previamente «se transfiguró (metamorphóze) ante» tres de ellos (Mc 9,2b), adquiriendo en esta ocasión tanto su rostro (Mt 17,2a) como sus vestidos (Mc 9,2; Mt 17,2b) la brillanted y blancura propios de los del Resucitado (Cf. Mc 16,5; Mt 28,3). Los tres evangelistas son, pues, unánimes en interpretar la transfiguración como un adelanto de la resurrección. Y esta concepción refleja también el autor de $2 \mathrm{Pe} 1,16-18$, cuando a sus destinatarios

64. Cf. H. SCHURMANN, o.c., («Der Paschamahlbericht...»), 34-46: 38ss; así también: W.G. Kummel, Verheissung, 24s; W. Grundmann, Lukas, 394; H. Conzelmann, Die Mitte, 106 (trad. españ., 167s); J. JEREMiAs, Abendmahlsworte Jesu, 156s (trad. españ., 178s); I.H. MARS. HALL, Luke, 799.

65. J. JEREMIAS, Theologie NT, 103 (trad. españ., 123). Su autenticidad histórica es altamente probable: Cf. R. PeSCH, Markus, II 66s; J. SCHLOSSER, o.c., 342-49. 
asegura, que les ha «dado a conocer el poder y la venida» del Señor Jesús (v. 16a), después de «haber visto... su majestad» (v. 16b) y haber escuchado la voz celeste «en el monte santo» (vv. 17-18). Tras este múltiple testimonio late, con toda probabilidad, un dato histórico: En la visión del Jesús transfigurado, los tres discípulos vieron anticipadamente al Señor resucitado, «constituido Hijo de Dios con poder» $(\mathrm{Rm} 1,4)$ sobre toda realidad de sufrimiento y de muerte. Pues $i$ «ha destruido la muerte» (2Tim 1,10$)$ aquél, sobre quien «la muerte ya no tiene señorío» (Rm 6,9). ¿Qué otra cosa, en efecto, significan los sustancialmente «históricos» relatos evangélicos sobre el sepulcro vacío y las apariciones del Resucitado, sino su victoria sobre el reinado del sheol o de la muerte, anticipadamente manifestada en su transfiguración? Una anticipación de la gloria del Señor resucitado «con poder» vieron, por tanto, los tres testigos del Jesús transfigurado, cumpliendo esta visión la previa promesa del Maestro sobre la visión del «Reinado de Dios venido con poder». Éste se identifica, pues, con el Señorío de Jesús sobre la muerte, inaugurado en su resurrección y anticipadamente manifestado en su transfiguración ${ }^{66}$.

c) Ahora podemos intentar aproximarnos a vislumbrar todo el alcance teológico de la súplica, que ruega al Padre por la «venida de su Reinado» (Lc $11,2=$ Mt 6,10). En ella enseñó ciertamente Jesús a sus discípulos una de las ideas centrales de su mensaje. Central es, en efecto, su predicación sobre el Reino y el Reinado de Dios, constituyendo precisamente esta súplica un texto clave de aquella enseñanza: Una «key Kingdon saying» ${ }^{67}$. Por lo demás, el objeto de la «venida» suplicada por los discípulos no es «el Reino» sino «el Reinado». Este significado, en efecto, envuelve «Basileia Tou Thoû» en todos los textos que se refieren a su «venida». Pues no viene un reino, sino la en él - por su señor o rey- ejercida potestad regia o señorío: Su reinado ${ }^{68}$. El original aramaico (= «malkut») de «Basileia», en esta súplica, debe ser traducido consecuentemente por «Reinado» ${ }^{69}$. ¿De quién?

66. La interpretación de Mc 9,1 en función de la transfiguración de Jesús como anticipación de su resurrección es sostenida últimamente por R. PESCH, Markus, II, 67.

67. B.D. ChILTON, O.c., 290.

68. Así con M.-J. LAgrange, Luc, 322; J. CARMignac, Recherches, 94; Id., Mirage..., 38; J. SCHLOSSER, o.c., 256.

69. El paralelo del «Qaddish» judaico, donde malkut traduce «el Señorío» de Dios, confirma la traducción de Basileia por «Reinado», como expresamente lo subraya G. DALMAN, o.c., 312. Esa traducción ofrecen asimismo varios comentaristas de Mt 6,10 (Th. ZAHN, W.C. AlLEN, M.-J. LAGRANGe, A. SchlatTer, J. SchNiewind, P. BonNARd, ad. loc.) y de Lc 11,2 (Th. ZAHN, A. Loisy, M.-J. Lagrange, A. Plummer, K.H. Rengstorf, J. Schmid, A.R.C Leaney, I.H. MARShall: ad loc.), los comentarios al Padrenuestro de: K.G. KuHN (Achtzehngebet, 42.43), R.E. Brown, (New Testament Essays, 233), J. CARMignaC, (Recherches, 91-98: 94), J. Jeremias, (Theologie NT, 192) y los estudios de: T.W. MANSON, Teaching, 126; W.G. KüMMEL, Verheis- 
La estructura literaria del Padrenuestro, a cuya invocación inicial siguen las dos primeras súplicas por lo que al «Padre» le pertenece, -la santificación de «su» nombre y la venida de «su» Reinado-, muestra claramente que se trata del Reinado del Padre ${ }^{70}$. Y ésta es otra novedad teológica de Jesús, quien no sólo habló expresamente del «Reino del Padre» (Cf. supra), sino también de «su Reinado», refiriéndose incluso al «Padre» siempre que predicó y enseñó sobre «el Reinado de Dios» (Cf. supra). Esto muestra, que, en el contexto de su mensaje central, la Realeza y la Paternidad de Dios están indisolublemente unidas ${ }^{71}$, constituyendo «la ilación entre Padre y Reinado» una definida característica de su predicación ${ }^{72}$. El Padre de Jesús y de sus discípulos es esencialmente Rey: ¡ «El gran Rey»! (Cf. Mt 5,35), proveniendo precisamente su dignidad regia de su Paternidad, como el agua de la fuente y la luz del sol. ;Dios es Rey, porque es Padre! Más aún: «Es el más verdadero Rey, porque es el más verdadero Padre» ${ }^{73}$. La paternidad divina, por tanto, se manifiesta en el ejercicio de su realeza, en la realización de su Reinado, siendo éste esencialmente un Reinado paterno. Lo que significa: El Padre ejerce su Señorío mostrándose Padre. Y lo hace, velando ciertamente con paternal providencia sobre todos los súbditos -incluso «los lirios del campo» y «las aves del cielo»- de su «Reino» $y$, de modo especial, sobre sus hijos ${ }^{74}$. Pero su paternal Señorío lo realiza también -y principalmente-mediante el ejercicio de lo que más esencialmente le caracteriza: el dominio de la misericordia, la potestad regia del perdón. Pues si «el Reinado es ciertamente la soberanía del Señor, concretamente y en profundidad se confunde con el pleno ejercicio de la misericordia del Padre» ${ }^{75}$. Así reina Dios! Siendo misericordioso, donando su perdón. Y esta cualidad regia le distingue de Marduk y de Apolo, de Isis, de Mitra, de Dionisios y de Allah: ¡de todos los dioses! El Dios, revelado por su

sung, 19; J. Bonsirven, Règne..., 59, 132.160s; X. Leon-Dufour, Les Évangiles...., 393 (jinexacta la trad. españ., 347: «Reino»!; N. PERRIN, Kingdom, 192; Id., Rediscovering, 160; Id., Language, 47; R. SCHNACKENBURG, Gottesherrschaft, 72.110; G.E. LADD, o.c., 132; J. SCHLOSSER, o.c., 256.

70. Esa relación entre «el Reinado» y «el Padre» en el contexto del padrenuestro, ignorada por casi todos los comentaristas de Mt y Lc (sólo una fugaz alusión ofrece W. GRUNDMANN, Matthäus, 201) así como por los comentarios a la «Oración del Señor» y por los estudios sobre la segunda súplica, ha sido subrayada por G.E. LADD, o.c., 175; J. SCHLOSSER, o.c., 682.

71. Cf. T.W. Manson, Teaching, 163s; C.J. CAdouX, Mission, 112s; G. SCHRENK, art. Páter, en: ThWNT, V 995s; G.E. LADD, o.c., 169.174-80; H. MERKLEIN, o.c., 209s; J. SCHLOSSER, o.c., 682-684.

72. G. SCHRENK, art. cit., 995 s. «El kerigma del Reinado de Dios, proclamado por Jesús, y el testimonio que él da sobre el Padre se corresponden estrechamente»: J. SCHLOSSER, o.c., 684.

73. T.W. MANSON, Teaching, 164.

74. Mt $6,25-33=$ Lc $12,22-30$.

75. Así concluye bellamente su voluminosa monografía J. SCHLosSER, o.c., 684. 
Hijo Jesús con «el Padre», reina amando y ama reinando: Reina, condonando a su siervo la insaldable deuda (Mt 18,23-27), antes de condenar sus despiadada conducta (Mt 18,28-34); reina, invitando al nupcial banquete de su Hijo a «malos y buenos» (Mt 22,2.9-10); reina, buscando la oveja perdida y abrazando con gozo al hijo pródigo; reina, haciendo llover y salir el sol también sobre «los malos» e «injustos», siendo «bueno con los ingratos y perversos», ...jDios reina, amando a los pecadores! Digámoslo sin ambages: El Señorío del Padre se refleja en el humanamente incomprensible ejercicio de su renovada misericordia y de su inagotable perdón. ¡Por medio de aquélla y éste reina principalmente, en esta tierra y sobre todo los hombres, Dios! El Reinado del Padre celeste consiste en el Señorío de su Amor.

Santos SABUGAL Inst. Patrístico «Agustinianum». Roma 